\title{
Fuzzy Hyers-Ulam approximation of a mixed AQ mapping
}

Hassan Azadi Kenary ${ }^{1}$, Saedeh Talebzadeh, Hamid Rezaei ${ }^{1}$, Jung Rye Lee ${ }^{3}$ and Dong Yun Shin ${ }^{4^{*}}$

* Correspondence: dyshin@uos.ac. $\mathrm{kr}$

${ }^{4}$ Department of Mathematics, University of Seoul, Seoul 130-743, Korea

Full list of author information is available at the end of the article

\section{Abstract}

In this article, we adopt the fixed point and direct methods to prove the Hyers-Ulam stability for an additive-quadratic functional equation in fuzzy Banach spaces.

Mathematics Subject Classification 2010: 39B52, 46S40; $26 E 50$.

Keywords: fuzzy Banach space, functional equation, fixed point, Hyers-Ulam stability

\section{Introduction and preliminaries}

A classical question in the theory of functional equations is the following: "When is it true that a function which approximately satisfies a functional equation must be close to an exact solution of the equation?". If the problem accepts a solution, we say that the equation is stable. The first stability problem concerning group homomorphisms was raised by Ulam [1]. In the next year, Hyers [2] gave a positive answer to the above question for additive groups under the assumption that the groups are Banach spaces. In 1978, Rassias [3] extended the theorem of Hyers by considering the unbounded Cauchy difference $\|f(x+y)-f(x)-f(y)\| \leq \varepsilon\left(\|x\|^{p}+\|y\|^{p}\right),(\varepsilon>0, p \in[0,1))$. Furthermore, in 1994, a generalization of Rassias' theorem was obtained by Găvruta [4] by replacing the bound $\epsilon\left(\|x\|^{p}+\|y\|^{p}\right)$ by a general control function $\phi(x, y)$.

In 1983, a Hyers-Ulam stability problem for the quadratic functional equation was proved by Skof [5] for mappings $f: X \rightarrow Y$, where $X$ is a normed space and $Y$ is a Banach space. In 1984, Cholewa [6] noticed that the theorem of Skof is still true if the relevant domain $X$ is replaced by an Abelian group and, in 2002, Czerwik [7] proved the Hyers-Ulam stability of the quadratic functional equation.

Katsaras [8] defined a fuzzy norm on a vector space to construct a fuzzy vector topological structure on the space. Some mathematicians have defined fuzzy norms of a vector space from various points of view (see [9-17]).

In particular, Bag and Samanta [18], following Cheng and Mordeson [19], gave an idea of fuzzy norm in such a manner that the corresponding fuzzy metric is of Karmosil and Michalek type [20]. They established a decomposition theorem of a fuzzy norm into a family of crisp norms and investigated some properties of fuzzy normed spaces [21].

In this article, we prove the Hyers-Ulam stability of the following additive-quadratic functional equation 


$$
\begin{aligned}
r^{2} f\left(\frac{x+y+z}{r}\right) & +r^{2} f\left(\frac{x-y+z}{r}\right)+r^{2} f\left(\frac{x+y-z}{r}\right)+r^{2} f\left(\frac{-x+y+z}{r}\right) \\
& =4 f(x)+4 f(y)+4 f(z)
\end{aligned}
$$

where $r$ is a positive real number, in fuzzy Banach spaces.

Lee and Jun [22] proved that an even (odd) mapping $f: X \rightarrow Y$ satisfies the functional Equation (1.1) if and only if the mapping $f: X \rightarrow Y$ is quadratic (additive). Moreover, they proved the Hyers-Ulam stability of the functional Equation (1.1) in nonArchimedean normed spaces. The stability problems of several functional equations have been extensively investigated by a number of authors, and there are many interesting results concerning this problem (see [23-33]).

Definition 1.1. [18] Let $X$ be a real vector space. A function $N: X \times \mathbb{R} \rightarrow[0,1]$ is called a fuzzy norm on $X$ if for all $x, y \in X$ and all $s, t \in \mathbb{R}$,

(N1) $N(x, t)=0$ for $t \leq 0$;

(N2) $x=0$ if and only if $N(x, t)=1$ for all $t>0$;

(N3) $N(c x, t)=N\left(x, \frac{t}{|c|}\right)$ if $c \neq 0$;

(N4) $N(x+y, c+t) \geq \min \{N(x, s), N(y, t)\}$;

(N5) $N\left(x\right.$, .) is a non-decreasing function of $\mathbb{R}$ and $\lim _{t \rightarrow \infty} N(x, t)=1$;

(N6) for $x \neq 0, N(x$, .) is continuous on $\mathbb{R}$.

The pair $(X, N)$ is called a fuzzy normed vector space.

Example 1.2. Let $(X,\|\cdot\|)$ be a normed linear space and $\alpha, \beta>0$. Then

$$
N(x, t)= \begin{cases}\frac{\alpha t}{\alpha t+\beta\|x\|} t>0, x \in X \\ 0 \quad t \leq 0, x \in X\end{cases}
$$

is a fuzzy norm on $X$.

Definition 1.3. [18] Let $(X, N)$ be a fuzzy normed vector space. A sequence $\left\{x_{n}\right\}$ in $X$ is said to be convergent or converge if there exists an $x \in X$ such that $\lim _{t \rightarrow \infty} N\left(x_{n}\right.$ $x, t)=1$ for all $t>0$. In this case, $x$ is called the limit of the sequence $\left\{x_{n}\right\}$ in $X$ and we denote it by $N-\lim _{t \rightarrow \infty} x_{n}=x$.

Definition 1.4. [18] Let $(X, N)$ be a fuzzy normed vector space. A sequence $\left\{x_{n}\right\}$ in $X$ is called Cauchy if for each $\epsilon>0$ and each $t>0$ there exists an $n_{0} \in \mathbb{N}$ such that for all $n \geq n_{0}$ and all $p>0$, we have $N\left(x_{n+p}-x_{n}, t\right)>1-\epsilon$.

It is well known that every convergent sequence in a fuzzy normed vector space is Cauchy. If each Cauchy sequence is convergent, then the fuzzy norm is said to be complete and the fuzzy normed vector space is called a fuzzy Banach space.

Example 1.5. Let $N: X \times \mathbb{R} \rightarrow[0,1]$ be a fuzzy norm on $\mathbb{R}$ defined by

$$
N(x, t)=\left\{\begin{array}{ll}
\frac{t}{t+|x|} t>0 \\
0 \quad t \leq 0
\end{array} .\right.
$$

Then $(\mathbb{R}, N)$ is a fuzzy Banach space. Let $\left\{x_{n}\right\}$ be a Cauchy sequence in $\mathbb{R}, \delta>0$ and $\varepsilon=\frac{\delta}{1+\delta}$. Then there exist $m \in \mathbb{N}$ such that for all $n \geq m$ and all $p>0$, we have 


$$
\frac{1}{1+\left|x_{n+p}-x_{n}\right|} \geq 1-\varepsilon
$$

So $\left|x_{n+p}-x_{n}\right|<\delta$ for all $n \geq m$ and all $p>0$. Therefore $\left\{x_{n}\right\}$ is a Cauchy sequence in $(\mathbb{R}$, $|\cdot|)$. Let $x_{n} \rightarrow x_{0} \in \mathbb{R}$ as $n \rightarrow \infty$. Then $\lim _{n \rightarrow \infty} N\left(x_{n}-x_{0}, t\right)=1$ for all $t>0$.

We say that a mapping $f: X \rightarrow Y$ between fuzzy normed vector spaces $X$ and $Y$ is continuous at a point $x \in X$ if for each sequence $\left\{x_{n}\right\}$ converging to $x_{0} \in X$, then the sequence $\left\{f\left(x_{n}\right)\right\}$ converges to $f\left(x_{0}\right)$. If $f: X \rightarrow Y$ is continuous at each $x \in X$, then $f$ : $X \rightarrow Y$ is said to be continuous on $X$ ([21]).

Definition 1.6. Let $X$ be a set. A function $d: X \times X \rightarrow[0, \infty]$ is called a generalized metric on $X$ if $d$ satisfies the following conditions:

(1) $d(x, y)=0$ if and only if $x=y$ for all $x, y \in X$;

(2) $d(x, y)=d(y, x)$ for all $x, y \in X$;

(3) $d(x, z) \leq d(x, y)+d(y, z)$ for all $x, y, z \in X$.

Theorem 1.7. Let $(X, d)$ be a complete generalized metric space and $J: X \rightarrow X$ be a strictly contractive mapping with Lipschitz constant $L<1$. Then, for all $x \in X$, either

$$
d\left(J^{n} x, J^{n+1} x\right)=\infty
$$

for all nonnegative integers $n$ or there exists a positive integer $n_{0}$ such that

(1) $d\left(J^{n} x, J^{n+1} x\right)<\infty$ for all $n_{0} \geq n_{0}$;

(2) the sequence $\left\{f^{n} x\right\}$ converges to a fixed point $y^{*}$ of $J$;

(3) $y^{*}$ is the unique fixed point of $J$ in the set $Y=\left\{y \in X: d\left(J^{n_{0}} x, y\right)<\infty\right\}$;

(4) $d\left(y, y^{*}\right) \leq \frac{1}{1-L} d(y, J y)$ for all $y \in Y$.

\section{Fuzzy stability of the functional equation (1.1): fixed point method}

In this section, using the fixed point method, we prove the Hyers-Ulam stability of the additive-quadratic functional equation (1.1) in fuzzy Banach spaces.

Remark 2.1. If $f$ be an odd mapping satisfying (1.1) and $r=2$, then an additive mapping $f$ is nonzero in general. But if $r$ is a rational number and $r \neq 2$ in (1.1), then $f \equiv 0$. So, to avoid the trivial case, let $r=2$ or $r$ is an positive irrational real number.

Theorem 2.2. Let $\phi: X^{3} \rightarrow[0, \infty)$ be a function such that there exists an $\alpha<1$ with

$$
\varphi(2 x, 2 y, 2 z) \leq 2 \alpha \varphi(x, y, z)
$$

for all $x, y, z \in X$. Let $f: X \rightarrow Y$ be an odd mapping satisfying

$$
\begin{aligned}
& N\left(r^{2} f\left(\frac{x+y+z}{r}\right)+r^{2} f\left(\frac{x-y+z}{r}\right)+r^{2} f\left(\frac{x+y-z}{r}\right)+r^{2} f\left(\frac{-x+y+z}{r}\right)\right. \\
& -4 f(x)-4 f(y)-4 f(z), t) \geq \frac{1}{t+\varphi(x, y, z)}
\end{aligned}
$$

for all $x, y, z \in X$ and all $t>0$. Then

$$
A(x):=N-\lim _{n \rightarrow \infty} \frac{f\left(2^{n} x\right)}{2^{n}}
$$


exists for each $x \in X$ and defines a unique additive mapping $A: X \rightarrow Y$ such that

$$
N(f(x)-A(x), t) \geq \frac{(4-4 \alpha) t}{(4-4 \alpha) t+\varphi(2 x, 0,0)+\varphi(x, x, 0)}
$$

Proof. Note that $f(0)=0$ and $f(-x)=-f(x)$ for all $x \in X$ since $f$ is an odd function. Putting $y=z=0$ in (2.2) and replacing $x$ by $2 x$, we get

$$
N\left(2 r^{2} f\left(\frac{2 x}{r}\right)-4 f(2 x), t\right) \geq \frac{t}{t+\varphi(2 x, 0,0)}
$$

for all $x \in X$ and all $t>0$. Putting $y=x$ and $z=0$ in (2.2), we have

$$
N\left(2 r^{2} f\left(\frac{2 x}{r}\right)-8 f(x), t\right) \geq \frac{t}{t+\varphi(x, x, 0)}
$$

for all $x \in X$ and all $t>0$. By (2.4), (2.5), (N3) and (N4), we get

$$
\begin{aligned}
N\left(\frac{f(2 x)}{2}-f(x), \frac{t}{4}\right) & =N\left(2 r^{2} f\left(\frac{2 x}{r}\right)-8 f(x)-2 r^{2} f\left(\frac{2 x}{r}\right)+4 f(2 x), 2 t\right) \\
& \geq \min \left\{N\left(2 r^{2} f\left(\frac{2 x}{r}\right)-4 f(2 x), t\right), N\left(2 r^{2} f\left(\frac{2 x}{r}\right)-8 f(x), t\right)\right\} \\
& \geq \frac{t}{t+\varphi(2 x, 0,0)+\varphi(x, x, 0)} .
\end{aligned}
$$

for all $x \in X$ and all $t>0$. Consider the set $S:=\{h: X \rightarrow Y\}$ and introduce the generalized metric on $S$ :

$$
d(g, h)=\inf _{\mu \in(0,+\infty)}\left\{N(g(x)-h(x), \mu t) \geq \frac{t}{t+\varphi(2 x, 0,0)+\varphi(x, x, 0)}, \quad \forall x \in X\right\},
$$

where, as usual, $\inf \varphi=+\infty$. It is easy to show that $(S, d)$ is complete (see [11]). Now we consider the linear mapping $J:(S, d) \rightarrow(S, d)$ such that

$$
J g(x):=\frac{1}{2} g(2 x)
$$

for all $x \in X$.

Let $g, h \in S$ be given such that $d(g, h)=\beta$. Then

$$
N(g(x)-h(x), \beta t) \geq \frac{t}{t+\varphi(2 x, 0,0)+\varphi(x, x, 0)}
$$

for all $x \in X$ and all $t>0$. Hence

$$
\begin{aligned}
N(J g(x)-J h(x), \alpha \beta t)=N\left(\frac{1}{2} g(2 x)-\frac{1}{2} h(2 x), \alpha \beta t\right) & =N(g(2 x)-h(2 x), 2 \alpha \beta t) \\
& \geq \frac{2 \alpha t}{2 \alpha t+\varphi(4 x, 0,0)+\varphi(2 x, 2 x, 0)} \\
& \geq \frac{2 \alpha t}{2 \alpha t+2 \alpha(\varphi(2 x, 0,0)+\varphi(x, x, 0))} \\
& =\frac{t}{t+\varphi(2 x, 0,0)+\varphi(x, x, 0)}
\end{aligned}
$$

for all $x \in X$ and all $t>0$. So $d(g, h)=\beta$ implies that $d(J g, J h) \leq \alpha \beta$. This means that $d(J g, J h) \leq \alpha d(g, h)$ for all $g, h \in S$. It follows from (2.6) that 


$$
d(f, J f) \leq \frac{1}{4}
$$

By Theorem 1.7, there exists a mapping $A: X \rightarrow Y$ satisfying the following:

(1) $A$ is a fixed point of $J$, i.e.,

$$
2 A(x)=A(2 x)
$$

for all $x \in X$. The mapping $A$ is a unique fixed point of $J$ in the set $M=\{g \in S: d$ $(h, g)<\infty\}$. This implies that $A$ is a unique mapping satisfying (2.7) such that there exists a $\mu \in(0, \infty)$ satisfying

$$
N(f(x)-A(x), \mu t) \geq \frac{t}{t+\varphi(2 x, 0,0)+\varphi(x, x, 0)}
$$

for all $x \in X$;

(2) $d\left(V^{n} f, A\right) \rightarrow 0$ as $n \rightarrow \infty$. This implies the equality $\lim _{n \rightarrow \infty} \frac{f\left(2^{n} x\right)}{2^{n}}=A(x)$ for all $x \in X$

(3) $d(f, A) \leq \frac{1}{1-\alpha} d(f, J f)$, which implies the inequality $d(f, A) \leq \frac{1}{4-4 \alpha}$. This implies that the inequalities (2.3) holds.

It follows from (2.1) and (2.2) that

$$
\begin{aligned}
& N\left(\frac { 1 } { 2 ^ { n } } \left[r^{2} f\left(\frac{2^{n}(x+y+z)}{r}\right)+r^{2} f\left(\frac{2^{n}(x-y+z)}{r}\right)+r^{2} f\left(\frac{2 n(x+y-z)}{r}\right)\right.\right. \\
& \left.\left.+r^{2} f\left(\frac{2^{n}(-x+y+z)}{r}\right)-4 f\left(2^{n} x\right)-4 f\left(2^{n} y\right)-4 f\left(2^{n} z\right)\right], \frac{1}{2^{n}}\right) \\
& \geq \frac{t}{t+\varphi\left(2^{n} x, 2^{n} y, 2^{n} z\right)}
\end{aligned}
$$

for all $x, y, z \in X$, all $t>0$ and all $n \in \mathbb{N}$. So

$$
\begin{aligned}
& N\left(\frac { 1 } { 2 ^ { n } } \left[r^{2} f\left(\frac{2^{n}(x+y+z)}{r}\right)+r^{2} f\left(\frac{2^{n}(x-y+z)}{r}\right)+r^{2} f\left(\frac{2^{n}(x+y-z)}{r}\right)\right.\right. \\
& \left.\left.+r^{2} f\left(\frac{2^{n}(-x+y+z)}{r}\right)-4 f\left(2^{n} x\right)-4 f\left(2^{n} y\right)-4 f\left(2^{n} z\right)\right], t\right) \\
& \geq \frac{2^{n} t}{2^{n} t+(2 \alpha)^{n} \varphi(x, y, z)}
\end{aligned}
$$

for all $x, y, z \in X$, all $t>0$ and all $n \in \mathbb{N}$. Since

$$
\lim _{n \rightarrow \infty} \frac{2^{n} t}{2^{n} t+(2 \alpha)^{n} \varphi(x, y, z)}=1
$$

for all $x, y, z \in X$ and all $t>0$, we obtain that

$$
\begin{aligned}
& N\left(r^{2} A\left(\frac{x+y+z}{r}\right)+2^{r} A\left(\frac{x-y+z}{r}\right)\right. \\
& \left.+r^{2} A\left(\frac{x+y-z}{r}\right)+r^{2} A\left(\frac{-x+y+z}{s}\right)-4 A(x)-4 A(y)-4 A(z), t\right)=1
\end{aligned}
$$


for all $x, y, z \in X$ and all $t>0$. Hence the mapping $A: X \rightarrow Y$ is additive, as desired.

Corollary 2.3. Let $\theta \geq 0$ and $r$ be a real positive number with $r<1$. Let $X$ be $a$ normed vector space with norm $\|\cdot\|$. Let $f: X \rightarrow Y$ be an odd mapping satisfying

$$
\begin{aligned}
& N\left(r^{2} f\left(\frac{x+y+z}{r}\right)+r^{2} f\left(\frac{x-y+z}{r}\right)+r^{2} f\left(\frac{x+y-z}{r}\right)+r^{2} f\left(\frac{-x+y+z}{r}\right)\right. \\
& -4 f(x)-4 f(y)-4 f(z), t) \geq \frac{t}{t+\theta\left(\|x\|^{r}+\|y\|^{r}+\|z\|^{r}\right)}
\end{aligned}
$$

for all $x, y, z \in X$ and all $t>0$. Then the limit $A(x):=N-\lim _{n \rightarrow \infty} \frac{f\left(2^{n} x\right)}{2^{n}}$ exists for each $x \in X$ and defines a unique additive mapping $A: X \rightarrow Y$ such that

$$
N(f(x)-A(x), t) \geq \frac{4\left(1-2^{r-1}\right) t}{4\left(1-2^{r-1}\right) t+\left(2^{r}+2\right) \theta\|x\|^{r}} .
$$

for all $x \in X$ and all $t>0$.

Proof. The proof follows from Theorem 2.2 by taking $\phi(x, y, z):=\theta\left(\|x\|^{r}+\|y\|^{r}+\right.$ $\left.\|z\|^{r}\right)$ for all $x, y, z \in X$. Then we can choose $\alpha=2^{r-1}$ and we get the desired result.

Theorem 2.4. Let $\phi: X^{3} \rightarrow[0, \infty)$ be a function such that there exists an $\alpha<1$ with

$$
\varphi\left(\frac{x}{2}, \frac{y}{2}, \frac{z}{2}\right) \leq \frac{\alpha}{2} \varphi(x, y, z)
$$

for all $x, y, z \in X$. Let $f: X \rightarrow Y$ be an odd mapping satisfying (2.2). Then the limit $A(x):=N-\lim _{n \rightarrow \infty} 2^{n} f\left(\frac{x}{2^{n}}\right)$ exists for each $x \in X$ and defines a unique additive mapping $A: X \rightarrow Y$ such that

$$
N(f(x)-A(x), t) \geq \frac{(4-4 \alpha) t}{(4-4 \alpha) t+\alpha(\varphi(2 x, 0,0)+\varphi(x, x, 0))}
$$

Proof. Let $(S, d)$ be the generalized metric space defined as in the proof of Theorem 2.2. Consider the linear mapping $J: S \rightarrow S$ such that

$$
J g(x):=2 g\left(\frac{x}{2}\right) .
$$

Let $g, h \in S$ be given such that $d(g, h)=\beta$. Then

$$
N(g(x)-h(x), \beta t) \geq \frac{t}{t+\varphi(2 x, 0,0)+\varphi(x, x, 0)}
$$

for all $x \in X$ and all $t>0$. Hence

$$
\begin{aligned}
N(J g(x)-J h(x), \alpha \beta t)=N\left(2 g\left(\frac{x}{2}\right)-2 h\left(\frac{x}{2}\right), \alpha \beta t\right) & =N\left(g\left(\frac{x}{2}\right)-g\left(\frac{x}{2}\right), \frac{\alpha \beta t}{2}\right) \\
& \geq \frac{\frac{\alpha}{2} t}{\frac{\alpha}{2} t+\varphi(x, 0,0)+\varphi\left(\frac{x}{2}, \frac{x}{2}, 0\right)} \\
& \geq \frac{t}{t+\varphi(2 x, 0,0)+\varphi(x, x, 0)}
\end{aligned}
$$

for all $x \in X$ and all $t>0$. So $d(g, h)=\beta$ implies that $d(J g, J h) \leq \alpha \beta$. This means that $d(J g, J h) \leq \alpha d(g, h)$ for all $g, h \in S$. It follows from (2.6) that 


$$
N\left(2 f\left(\frac{x}{2}\right)-f(x), \frac{t}{2}\right) \geq \frac{t}{t+\varphi(x, 0,0)+\varphi\left(\frac{x}{2}, \frac{x}{2}, 0\right)} \geq \frac{t}{t+\frac{\alpha}{2}(\varphi(2 x, 0,0)+\varphi(x, x, 0))}
$$

for all $x \in X$ and $t>0$. Therefore

$$
N\left(2 f\left(\frac{x}{2}\right)-f(x), \frac{\alpha t}{4}\right) \geq \frac{t}{t+\varphi(2 x, 0,0)+\varphi(x, x, 0)} .
$$

So $d(f$, Jf $) \leq \frac{\alpha}{4}$. By Theorem 1.7, there exists a mapping $A: X \rightarrow Y$ satisfying the following:

(1) $A$ is a fixed point of $J$, that is,

$$
A\left(\frac{x}{2}\right)=\frac{1}{2} A(x)
$$

for all $x \in X$. The mapping $A$ is a unique fixed point of $J$ in the set $\Omega=\{h \in S: d(g$, $h)<\infty\}$. This implies that $A$ is a unique mapping satisfying (2.12) such that there exists $\mu \in(0, \infty)$ satisfying

$$
N(f(x)-A(x), \mu t) \geq \frac{t}{t+\varphi(2 x, 0,0)+\varphi(x, x, 0)}
$$

for all $x \in X$ and $t>0$.

(2) $d\left(J^{n} f, A\right) \rightarrow 0$ as $n \rightarrow \infty$. This implies the equality $N-\lim _{n \rightarrow \infty} 2^{n} f\left(\frac{x}{2^{n}}\right)=A(x)$ for all $x \in X$.

(3) $d(f, A) \leq \frac{d(f, J f)}{1-L}$ with $f \in \Omega$, which implies the inequality $d(f, A) \leq \frac{\alpha}{4-4 \alpha}$.

This implies that the inequality (2.10) holds.

The rest of the proof is similar to that of the proof of Theorem 2.2.

Corollary 2.5. Let $\theta \geq 0$ and let $r$ be a real number with $r>1$. Let $X$ be a normed vector space with norm $\|\cdot\|$. Let $f: X \rightarrow Y$ be an odd mapping satisfying (2.8). Then, the limit $A(x):=N-\lim _{n \rightarrow \infty} 2^{n} f\left(\frac{x}{2^{n}}\right)$ exists for each $x \in X$ and defines a unique additive mapping $A: X \rightarrow Y$ such that

$$
N(f(x)-A(x), t) \geq \frac{4\left(2^{r}-2\right) t}{4\left(2^{r}-2\right) t+\left(2^{r+1}+4\right) \theta\|x\|^{r}} .
$$

for all $x \in X$ and all $t>0$.

Proof. The proof follows from Theorem 2.4 by taking $\phi(x, y, z):=\theta\left(\|x\|^{r}+\|y\|^{r}+\right.$ $\|z\|^{r}$ ) for all $x, y, z \in X$. Then we can choose $\alpha=2^{1-r}$ and we get the desired result.

Theorem 2.6. Let $\phi: X^{3} \rightarrow[0, \infty)$ be a function such that there exists an $\alpha<1$ with

$$
\varphi(2 x, 2 y, 2 z) \leq 4 \alpha \varphi(x, y, z)
$$

for all $x, y, z \in X$. Let $f: X \rightarrow Y$ be an even mapping with $f(0)=0$ and satisfying (2.2). Then $Q(x):=N-\lim _{n \rightarrow \infty} \frac{f\left(2^{n} x\right)}{4^{n}}$ exists for each $x \in X$ and defines a unique 
quadratic mapping $Q: X \rightarrow Y$ such that

$$
N(f(x)-Q(x), t) \geq \frac{(8-8 \alpha) t}{(8-8 \alpha) t+3(\varphi(2 x, 0,0)+\varphi(x, x, 0))}
$$

Proof. Putting $y=x$ and $z=0$ in (2.2), we get

$$
N\left(2 r^{2} f\left(\frac{2 x}{r}\right)-8 f(x), t\right) \geq \frac{t}{t+\varphi(x, x, 0)}
$$

for all $x \in X$ and all $t>0$. Putting $y=z=0$ and replacing $x$ by $2 x$ in (2.2), we have

$$
N\left(4 r^{2} f\left(\frac{2 x}{r}\right)-4 f(2 x), t\right) \geq \frac{t}{t+\varphi(2 x, 0,0)}
$$

for all $x \in X$ and all $t>0$. By (2.15), (2.16), (N3) and (N4), we get

$$
\begin{aligned}
N\left(\frac{f(2 x)}{4}-f(x), \frac{t}{16}\right) & =N\left(2\left(2 r^{2} f\left(\frac{2 x}{r}\right)-8 f(x)\right)-\left(4 r^{2} f\left(\frac{2 x}{r}\right)-4 f(2 x)\right), t\right) \\
& \geq \min \left\{N\left(2 r^{2} f\left(\frac{2 x}{r}\right)-8 f(x), \frac{t}{4}\right), N\left(4 r^{2} f\left(\frac{2 x}{r}\right)-4 f(2 x), \frac{t}{2}\right)\right\}
\end{aligned}
$$

for all $x \in X$ and all $t>0$. So

$$
\begin{aligned}
N\left(\frac{f(2 x)}{4}-f(x), \frac{3 t}{8}\right) & \geq \min \left\{N\left(2 r^{2} f\left(\frac{2 x}{r}\right)-8 f(x), t\right), N\left(4 r^{2} f\left(\frac{2 x}{r}\right)-4 f(x), t\right)\right\} \\
& \geq \frac{t}{t+\varphi(x, x, 0)+\varphi(2 x, 0,0)} .
\end{aligned}
$$

Consider the set $S^{*}:=\{h: X \rightarrow Y ; h(0)=0\}$ and introduce the generalized metric on $S^{*}$ :

$$
d(g, h)=\inf _{\mu \in(0,+\infty)}\left\{N(g(x)-h(x), \mu t) \geq \frac{t}{t+\varphi(2 x, 0,0)+\varphi(x, x, 0)}, \quad \forall x \in X\right\},
$$

where, as usual, inf $\varphi=+\infty$. It is easy to show that $\left(S^{*}, d\right)$ is complete (see [11]). Now we consider the linear mapping $J:\left(S^{*}, d\right) \rightarrow\left(S^{*}, d\right)$ such that $J g(x):=\frac{1}{4} g(2 x)$ for all $x \in X$. Proceeding as in the proof of Theorem 2.2, we obtain that $d(g, h)=\beta$ implies that $d(J g, J h) \leq \alpha \beta$. This means that $d(J g, J h) \leq \alpha d(g, h)$ for all $g, h \in S$. It follows from (2.17) that

$$
d(f, J f) \leq \frac{3}{8} .
$$

By Theorem 1.7, there exists a mapping $Q: X \rightarrow Y$ satisfying the following:

(1) $Q$ is a fixed point of $J$, i.e.,

$$
4 Q(x)=Q(2 x)
$$

for all $x \in X$. The mapping $Q$ is a unique fixed point of $J$ in the set $M=\left\{g \in S^{*}: d\right.$ $(h, g)<\infty\}$. This implies that $Q$ is a unique mapping satisfying $(2.18)$ such that there exists a $\mu \in(0, \infty)$ satisfying $N(f(x)-Q(x), \mu t) \geq \frac{t}{t+\varphi(2 x, 0,0)+\varphi(x, x, 0)}$ for all $x$ 
(2) $d\left(J^{n} f, Q\right) \rightarrow 0$ as $n \rightarrow \infty$. This implies the equality $\lim _{n \rightarrow \infty} \frac{f\left(2^{n} x\right)}{4^{n}}=Q(x)$ for all $x \in X$;

(3) $d(f, Q) \leq \frac{1}{1-\alpha} d(f, J f)$, which implies the inequality $d(f, Q) \leq \frac{3}{8-8 \alpha}$. This implies that the inequalities (2.14) holds.

The rest of the proof is similar to the proof of Theorem 2.2.

Corollary 2.7. Let $\theta \geq 0$ and $r$ be a real positive number with $r<1$. Let $X$ be $a$ normed vector space with norm $\|\cdot\|$. Let $f: X \rightarrow Y$ be an even mapping satisfying (2.8) and $f(0)=0$. Then the limit $Q(x):=N-\lim _{n \rightarrow \infty} \frac{f\left(2^{n} x\right)}{4^{n}}$ exists for each $x \in X$ and defines a unique quadratic mapping $Q: X \rightarrow Y$ such that

$$
N(f(x)-Q(x), t) \geq \frac{2\left(4-4^{r}\right) t}{2\left(4-4^{r}\right) t+3\left(2^{r}+2\right) \theta\|x\|^{r}} .
$$

for all $x \in X$ and all $t>0$.

Proof. The proof follows from Theorem 2.6 by taking $\phi(x, y, z):=\theta\left(\|x\|^{r}+\|y\|^{r}+\right.$ $\|z\|^{r}$ ) for all $x, y, z \in X$. Then we can choose $\alpha=4^{r-1}$ and we get the desired result.

Theorem 2.8. Let $\phi: X^{3} \rightarrow[0, \infty)$ be a function such that there exists an $\alpha<1$ with

$$
\varphi\left(\frac{x}{2}, \frac{y}{2}, \frac{z}{2}\right) \leq \frac{\alpha}{4} \varphi(x, y, z)
$$

for all $x, y, z \in X$. Let $f: X \rightarrow Y$ be an even mapping satisfying (2.2) and $f(0)=0$. Then the limit $Q(x):=N-\lim _{n \rightarrow \infty} 4^{n} f\left(\frac{x}{2^{n}}\right)$ exists for each $x \in X$ and defines $a$ unique quadratic mapping $Q: X \rightarrow Y$ such that

$$
N(f(x)-Q(x), t) \geq \frac{(8-8 \alpha) t}{(8-8 \alpha) t+3 \alpha(\varphi(2 x, 0,0)+\varphi(x, x, 0))}
$$

Proof. Let $\left(S^{*}, d\right)$ be the generalized metric space defined as in the proof of Theorem 2.6.

It follows from (2.17) that

$$
N\left(f(x)-4 f\left(\frac{x}{2}\right), \frac{3 t}{2}\right) \geq \frac{t}{t+\varphi(x, 0,0)+\varphi\left(\frac{x}{2}, \frac{x}{2}, 0\right)} \geq \frac{t}{t+\frac{\alpha}{4}(\varphi(2 x, 0,0)+\varphi(x, x, 0))}
$$

for all $x \in X$ and $t>0$. So

$$
N\left(f(x)-4 f\left(\frac{x}{2}\right), \frac{3 \alpha t}{8}\right) \geq \frac{t}{t+\varphi(2 x, 0,0)+\varphi(x, x, 0)} .
$$

The rest of the proof is similar to the proof of Theorems 2.2 and 2.4.

Corollary 2.9. Let $\theta \geq 0$ and $r$ be a real number with $r>1$. Let $X$ be a normed vector space with norm $\|\cdot\|$. Let $f: X \rightarrow Y$ be an even mapping satisfying $f(0)=0$ and (2.8).

Then $Q(x):=N-\lim _{n \rightarrow \infty} 4^{n} f\left(\frac{x}{2^{n}}\right)$ exists for each $x \in X$ and defines a unique 
quadratic mapping $Q: X \rightarrow Y$ such that

$$
N(f(x)-Q(x), t) \geq \frac{2\left(4^{r+1}-16\right) t}{2\left(4^{r+1}-16\right) t+3\left(2^{r+2}+8\right) \theta\|x\| r} .
$$

for all $x \in X$ and all $t>0$.

Proof. The proof follows from Theorem 2.8 by taking $\phi(x, y, z):=\theta\left(\|x\|^{r}+\|y\|^{r}+\right.$ $\left.\|z\|^{r}\right)$ for all $x, y, z \in X$. Then we can choose $\alpha=4^{1-r}$ and we get the desired result.

Let $f: X \rightarrow Y$ be a mapping satisfying $f(0)=0$ and (1.1). Let $f_{e}(x):=\frac{f(x)+f(-x)}{2}$ and $f_{o}(x)=\frac{f(x)-f(-x)}{2}$. Then $f_{e}$ is an even mapping satisfying (1.1) and $f_{o}$ is an odd mapping satisfying (1.1) such that $f(x)=f_{e}(x)+f_{o}(x)$. So we obtain the following.

Theorem 2.10. Let $\phi: X^{3} \rightarrow[0, \infty)$ be a function such that there exists an $\alpha<1$ with

$$
\varphi\left(\frac{x}{2}, \frac{y}{2}, \frac{z}{2}\right) \leq \frac{\alpha}{4} \varphi(x, y, z)
$$

for all $x, y, z \in X$. Let $f: X \rightarrow Y$ be a mapping satisfying (2.2) and $f(0)=0$. Then there exist a unique additive mapping $A: X \rightarrow Y$ and a unique quadratic mapping $Q$ : $X \rightarrow Y$ such that

$$
\begin{aligned}
& N(f(x)-A(x)-Q(x), 2 t) \\
& =N\left(\frac{f(x)-f(-x)}{2}+\frac{f(x)+f(-x)}{2}-A(x)-Q(x), 2 t\right) \\
& \geq \min \left\{N\left(\frac{f(x)-f(-x)}{2}-A(x), t\right), N\left(\frac{f(x)+f(-x)}{2}-Q(x), t\right)\right\} \\
& \geq \min \left\{\frac{(8-8 \alpha) t}{(8-8 \alpha) t+\alpha(\varphi(2 x, 0,0)+\varphi(x, x, 0))}, \frac{(8-8 \alpha) t}{(8-8 \alpha) t+3 \alpha(\varphi(2 x, 0,0)+\varphi(x, x, 0))}\right\} \\
& =\frac{(8-8 \alpha) t}{(8-8 \alpha) t+3 \alpha(\varphi(2 x, 0,0)+\varphi(x, x, 0))} .
\end{aligned}
$$

Corollary 2.11. Let $\theta \geq 0$ and let $r$ be a real number with $r>1$. Let $X$ be a normed vector space with norm $\|\cdot\|$. Let $f: X \rightarrow Y$ be a mapping with $f(0)=0$ and satisfying (2.8). Then there exist a unique additive mapping $A: X \rightarrow Y$ and a unique quadratic mapping $Q: X \rightarrow Y$ such that

$$
N(f(x)-A(x)-Q(x), t) \geq \frac{2\left(2^{r}-2\right) t}{2\left(2^{r}-2\right) t+3\left(2^{r}+2\right) \theta\|x\|^{r}} .
$$

for all $x \in X$ and all $t>0$.

Proof. The proof follows from Theorem 2.10 by taking $\phi(x, y, z):=\theta\left(\|x\|^{r}+\|y\|^{r}+\right.$ $\|z\|^{r}$ ) for all $x, y, z \in X$. Then we can choose $\alpha=2^{1-r}$ and we get the desired result.

\section{Fuzzy stability of the functional equation (1.1): a direct method}

In this section, using direct method, we prove the Hyers-Ulam stability of functional equation (1.1) in fuzzy Banach spaces. Throughout this section, we assume that $X$ is a linear space, $(Y, N)$ is a fuzzy Banach space and $\left(Z, N^{\prime}\right)$ is a fuzzy normed spaces. Moreover, we assume that $N(x,$.$) is a left continuous function on \mathbb{R}$.

Theorem 3.1. Assume that a mapping $f: X \rightarrow Y$ is an odd mapping satisfying the inequality 


$$
\begin{aligned}
& N\left(r^{2} f\left(\frac{x+y+z}{r}\right)+r^{2} f\left(\frac{x-y+z}{r}\right)+r^{2} f\left(\frac{x+y-z}{r}\right)+r^{2} f\left(\frac{-x+y+z}{r}\right)\right. \\
& -4 f(x)-4 f(y)-4 f(z), t) \geq N^{\prime}(\varphi(x, y, z), t)
\end{aligned}
$$

for all $x, y, z \in X, t>0$ and that $\phi: X^{3} \rightarrow Z$ is a mapping for which there is a constant $r \in \mathbb{R}$ satisfying $0<|r|<\frac{1}{2}$ such that

$$
N^{\prime}\left(\varphi\left(\frac{x}{2}, \frac{y}{2}, \frac{z}{2}\right), t\right) \geq N^{\prime}\left(\varphi(x, y, z), \frac{t}{|r|}\right)
$$

for all $x, y, z \in X$ and all $t>0$. Then there exists a unique additive mapping $A: X \rightarrow$ $Y$ satisfying (1.1) and the inequality

$$
N(f(x)-A(x), t) \geq \min \left\{N^{\prime}(\varphi(x, 0,0), 2(1-2|r|) t), N^{\prime}\left(\varphi(x, x, 0), \frac{2(1-2|r| t)}{|r|}\right)\right\}
$$

for all $x \in X$ and all $t>0$.

Proof. It follows from (3.2) that

$$
N^{\prime}\left(\varphi\left(\frac{x}{2^{j}}, \frac{y}{2^{j}}, \frac{z}{2^{j}}\right), t\right) \geq N^{\prime}\left(\varphi(x, y, z), \frac{t}{|r|^{j}}\right)
$$

for all $x, y, z \in X$ and all $t>0$. Putting $y=z=0$ in (3.1) and replacing $x$ by $2 x$, we get

$$
N\left(2 r^{2} f\left(\frac{2 x}{r}\right)-4 f(2 x), t\right) \geq N^{\prime}(\varphi(2 x, 0,0), t)
$$

for all $x \in X$ and all $t>0$. Putting $y=x$ and $z=0$ in (3.1), we have

$$
N\left(2 r^{2} f\left(\frac{2 x}{r}\right)-8 f(x), t\right) \geq N^{\prime}(\varphi(x, x, 0), t)
$$

for all $x \in X$ and all $t>0$. By (3.4), (3.5), (N3) and (N4), we get

$$
\begin{aligned}
N\left(\frac{f(2 x)}{2}-f(x), \frac{t}{4}\right) & =N\left(2 r^{2} f\left(\frac{2 x}{r}\right)-8 f(x)-2 r^{2} f\left(\frac{2 x}{r}\right)+4 f(2 x), 2 t\right) \\
& \geq \min \left\{N\left(2 r^{2} f\left(\frac{2 x}{r}\right)-4 f(2 x), t\right), N\left(2 r^{2} f\left(\frac{2 x}{r}\right)-8 f(x), t\right)\right\} \\
& \geq \min \left\{N^{\prime}(\varphi(2 x, 0,0), t), N^{\prime}(\varphi(x, x, 0), t)\right\}
\end{aligned}
$$

for all $x \in X$ and all $t>0$. Replacing $x$ by $\frac{x}{2}$ in (3.6), we have

$$
N\left(f(x)-2 f\left(\frac{x}{2}\right), \frac{t}{2}\right) \geq \min \left\{N^{\prime}(\varphi(x, 0,0), t), N^{\prime}\left(\varphi\left(\frac{x}{2}, \frac{x}{2}, 0\right), t\right)\right\} .
$$

Replacing $x$ by $\frac{x}{2^{j}}$ in (3.7), we have

$$
\begin{aligned}
& N\left(2^{j+1} f\left(\frac{x}{2^{j+1}}\right)-2^{j} f\left(\frac{x}{2^{j}}\right), 2^{j-1} t\right) \\
& \geq \min \left\{N^{\prime}\left(\varphi\left(\frac{x}{2^{j}}, 0,0\right), t\right), N^{\prime}\left(\varphi\left(\frac{x}{2^{j+1}}, \frac{x}{2^{j+1}}, 0\right), t\right)\right\} \\
& \geq \min \left\{N^{\prime}\left(\varphi(x, 0,0), \frac{t}{|r|^{j}}\right), N^{\prime}\left(\varphi(x, x, 0), \frac{t}{|r|^{j+1}}\right)\right\}
\end{aligned}
$$


for all $x \in X$, all $t>0$ and any integer $j \geq 0$. So

$$
\begin{aligned}
N\left(f(x)-2^{n} f\left(\frac{x}{2^{n}}\right), \sum_{j=0}^{n-1} 2^{j-1}|r|^{j} t\right) & =N\left(\sum_{j=0}^{n-1} 2^{j+1} f\left(\frac{x}{2^{j+1}}\right)-2^{j} f\left(\frac{x}{2^{j}}\right), \sum_{j=0}^{n-1} 2^{j-1}|r|^{j} t\right) \\
& \geq \min _{0 \leq j \leq n-1}\left\{N\left(2^{j+1} f\left(\frac{x}{2^{j+1}}\right)-2^{j} f\left(\frac{x}{2^{j}}\right), 2^{j-1}|r|^{j} t\right)\right\} \\
& \geq \min \left\{N^{\prime}(\varphi(x, 0,0), t), N^{\prime}\left(\varphi(x, x, 0), \frac{t}{|r|}\right)\right\}
\end{aligned}
$$

which yields

$$
\begin{aligned}
& N\left(2^{n+p} f\left(\frac{x}{2^{n+p}}\right)-2^{p} f\left(\frac{x}{2^{p}}\right), \sum_{j=0}^{n-1} 2^{j+p-1}|r|^{j}\right) \\
& \geq \min \left\{N^{\prime}\left(\varphi\left(\frac{x}{2^{p}}, 0,0\right), t\right), N^{\prime}\left(\varphi\left(\frac{x}{2^{p}}, \frac{x}{2^{p}}, 0\right), \frac{t}{|r|}\right)\right\} \\
& \geq \min \left\{N^{\prime}\left(\varphi(x, 0,0), \frac{t}{|r|^{p}}\right), N^{\prime}\left(\varphi(x, x, 0), \frac{t}{|r|^{p+1}}\right)\right\}
\end{aligned}
$$

for all $x \in X, t>0$ and any integers $n>0, p \geq 0$. So

$$
N\left(2^{n+p} f\left(\frac{x}{2^{n+p}}\right)-2^{p} f\left(\frac{x}{2^{p}}\right), \sum_{j=0}^{n-1} 2^{j+p-1} \mid r r^{j+p} t\right) \geq \min \left\{N^{\prime}(\varphi(x, 0,0), t), N^{\prime}\left(\varphi(x, x, 0), \frac{t}{|r|}\right)\right\}
$$

for all $x \in X, t>0$ and any integers $n>0, p \geq 0$. Hence one obtains

$$
\begin{aligned}
& N\left(2^{n+p} f\left(\frac{x}{2^{n+p}}\right)-2^{p} f\left(\frac{x}{2^{p}}\right), t\right) \\
& \geq \min \left\{N^{\prime}\left(\varphi(x, 0,0), \frac{t}{\sum_{j=0}^{n-1} 2^{j+p-1}|r|^{j+p}}\right), N^{\prime}\left(\varphi(x, x, 0), \frac{t}{\sum_{j=0}^{n-1} 2^{j+p-1}|r|^{j+p+1}}\right)\right\}
\end{aligned}
$$

for all $x \in X, t>0$ and any integers $n>0, p \geq 0$. Since the series $\sum_{j=0}^{+\infty} 2^{j}|r|^{j}$ is a convergent series, we see by taking the limit $p \rightarrow \infty$ in the last inequality that the sequence $\left\{2^{n} f\left(\frac{x}{2^{n}}\right)\right\}$ is a Cauchy sequence in the fuzzy Banach space $(Y, N)$ and so it converges in $Y$. Therefore a mapping $A: X \rightarrow Y$ defined by $A(x):=N-\lim _{n \rightarrow \infty} 2^{n} f\left(\frac{x}{2^{n}}\right)$ is well-defined for all $x \in X$. It means that

$$
\lim _{n \rightarrow \infty} N\left(A(x)-2^{n} f\left(\frac{x}{2^{n}}\right), t\right)=1
$$

for all $x \in X$ and all $t>0$. In addition, it follows from (3.10) that

$$
N\left(f(x)-2^{n} f\left(\frac{x}{2^{n}}\right), t\right) \geq \min \left\{N^{\prime}\left(\varphi(x, 0,0), \frac{2 t}{\sum_{j=0}^{n-1} 2 j|r|^{j}}\right), N^{\prime}\left(\varphi(x, x, 0), \frac{2 t}{\sum_{j=0}^{n-1} 2 j|r|^{j+1}}\right)\right\}
$$

for all $x \in X$ and all $t>0$. So

$$
\begin{aligned}
N(f(x)-A(x), t) & \geq \min \left\{N\left(f(x)-2^{n} f\left(\frac{x}{2^{n}}\right),(1-\varepsilon) t\right), N\left(A(x)-2^{n} f\left(\frac{x}{2^{n}}\right), \varepsilon t\right)\right\} \\
& \geq \min \left\{N^{\prime}\left(\varphi(x, 0,0), \frac{2 \varepsilon t}{\sum_{j=0}^{n-1} 2^{j}|r|^{j}}\right), N^{\prime}\left(\varphi(x, x, 0), \frac{2 \varepsilon t}{\sum_{j=0}^{n-1} 2^{j} \mid r r^{j+1}}\right)\right\} \\
& \geq \min \left\{N^{\prime}(\varphi(x, 0), 2(1-2)|r| \varepsilon t), N^{\prime}\left(\varphi(x, x, 0), \frac{2(1-2|r|) \varepsilon t}{|r|}\right)\right\}
\end{aligned}
$$


for sufficiently large $n$ and for all $x \in X, t>0$ and $\epsilon$ with $0<\epsilon<1$. Since $\epsilon$ is arbitrary and $N$ is left continuous, we obtain

$$
N(f(x)-A(x), t) \geq \min \left\{N^{\prime}(\varphi(x, 0,0), 2(1-2|r|) t), N^{\prime}\left(\varphi(x, x, 0), \frac{2(1-2|r| t)}{|r|}\right)\right\}
$$

for all $x \in X$ and $t>0$. It follows from (3.1) that

$$
\begin{aligned}
& N\left(2^{n} r^{2} f\left(\frac{x+y+z}{r \cdot 2^{n}}\right)+2^{n} \cdot r^{2} f\left(\frac{x-y+z}{r \cdot 2^{n}}\right)+2^{n} \cdot r^{2} f\left(\frac{x+y-z}{r \cdot 2^{n}}\right)+2^{n} \cdot r^{2} f\left(\frac{-x+y+z}{r \cdot 2^{n}}\right)\right. \\
& \left.-2^{n+2} f\left(\frac{x}{2^{n}}\right)-2^{n+2} f\left(\frac{y}{2^{n}}\right)-2^{n+2} f\left(\frac{z}{2^{n}}\right), t\right) \\
& \geq N^{\prime}\left(\varphi\left(\frac{x}{2^{n}}, \frac{y}{2^{n}}, \frac{z}{2^{n}}\right), \frac{t}{2^{n}}\right) \geq N^{\prime}\left(\varphi(x, y, z), \frac{t}{2^{n}|r|^{n}}\right) \rightarrow 1 \text { as } n \rightarrow+\infty
\end{aligned}
$$

for all $x, y, z \in X, t>0$. So

$$
\begin{aligned}
& N\left(2^{n} r^{2} f\left(\frac{x+y+z}{r \cdot 2^{n}}\right)+2^{n} \cdot r^{2} f\left(\frac{x-y+z}{r \cdot 2^{n}}\right)+2^{n} \cdot r^{2} f\left(\frac{x+y-z}{r \cdot 2^{n}}\right)+2^{n} \cdot r^{2} f\left(\frac{-x+y+z}{r \cdot 2^{n}}\right)\right. \\
& \left.-2^{n+2} f\left(\frac{x}{2^{n}}\right)-2^{n+2} f\left(\frac{y}{2^{n}}\right)-2^{n+2} f\left(\frac{z}{2^{n}}\right), t\right) \rightarrow 1
\end{aligned}
$$

for all $x, y, z \in X$ and all $t>0$. Therefore, we obtain in view of (3.11)

$$
\begin{aligned}
& N\left(r^{2} A\left(\frac{x+y+z}{r}\right)+r^{2} A\left(\frac{x-y+z}{r}\right)+r^{2} A\left(\frac{x+y-z}{r}\right)+r^{2} A\left(\frac{-x+y+z}{r}\right)\right. \\
- & 4 A(x)-4 A(y)-4 A(z), t) \\
\geq & \min \left\{N \left(r^{2} A\left(\frac{x+y+z}{r}\right)+r^{2} A\left(\frac{x-y+z}{r}\right)+r^{2} A\left(\frac{x+y-z}{r}\right)+r^{2} A\left(\frac{-x+y+z}{r}\right)\right.\right. \\
- & 4 A(x)-4 A(y)-4 A(z)-2^{n} r^{2} f\left(\frac{x+y+z}{r \cdot 2^{n}}\right)+2^{n} \cdot r^{2} f\left(\frac{x-y+z}{r \cdot 2^{n}}\right)+2^{n} \cdot r^{2} f\left(\frac{x+y-z}{r \cdot 2^{n}}\right) \\
& \left.+2^{n} \cdot r^{2} f\left(\frac{-x+y+z}{r \cdot 2^{n}}\right)-2^{n+2} f\left(\frac{x}{2^{n}}\right)-2^{n+2} f\left(\frac{y}{2^{n}}\right)-2^{n+2} f\left(\frac{z}{2^{n}}\right), \frac{t}{2}\right) \\
& N\left(2^{n} r^{2} f\left(\frac{x+y+z}{r \cdot 2^{n}}\right)+2^{n} \cdot r^{2} f\left(\frac{x-y+z}{r \cdot 2^{n}}\right)+2^{n} \cdot r^{2} f\left(\frac{x+y-z}{r \cdot 2^{n}}\right)+2^{n} \cdot r^{2} f\left(\frac{-x+y+z}{r \cdot 2^{n}}\right)\right. \\
& \left.\left.-2^{n+2} f\left(\frac{x}{2^{n}}\right)-2^{n+2} f\left(\frac{y}{2^{n}}\right)-2^{n+2} f\left(\frac{z}{2^{n}}\right), \frac{t}{2}\right)\right\} \\
& =N\left(2^{n} r^{2} f\left(\frac{x+y+z}{r \cdot 2^{n}}\right)+2^{n} \cdot r^{2} f\left(\frac{x-y+z}{r \cdot 2^{n}}\right)+2^{n} \cdot r^{2} f\left(\frac{x+y-z}{r \cdot 2^{n}}\right)+2^{n} \cdot r^{2} f\left(\frac{-x+y+z}{r \cdot 2^{n}}\right)\right. \\
& \left.-2^{n+2} f\left(\frac{x}{2^{n}}\right)-2^{n+2} f\left(\frac{y}{2^{n}}\right)-2^{n+2} f\left(\frac{z}{2^{n}}\right), \frac{t}{2}\right) \quad(\text { for sufficiently large } n) \\
\geq & N^{\prime}\left(\varphi(x, y, z), \frac{t}{2^{n+1}|r|^{n}}\right) \rightarrow 1 \text { as } n \rightarrow \infty
\end{aligned}
$$

which implies

$$
r^{2} A\left(\frac{x+y+z}{r}\right)+r^{2} A\left(\frac{x-y+z}{r}\right)+r^{2} A\left(\frac{x+y-z}{r}\right)+r^{2} A\left(\frac{-x+y+z}{r}\right)=4 A(x)+4 A(y)+4 A(z)
$$

for all $x, y, z \in X$. Thus $A: X \rightarrow Y$ is a mapping satisfying the Equation (1.1) and the inequality (3.3). Thus the mapping $A: X \rightarrow Y$ is additive, as desired.

To prove the uniqueness, assume that there is another mapping $L: X \rightarrow Y$ which satisfies the inequality (3.3). Since $L\left(2^{n} x\right)=2^{n} L(x)$ for all $x \in X$, we have 


$$
\begin{aligned}
N(A(x)-L(x), t) & =N\left(2^{n} A\left(\frac{x}{2^{n}}\right)-2^{n} L\left(\frac{x}{2^{n}}\right), t\right) \\
& \geq \min \left\{N\left(2^{n} A\left(\frac{x}{2^{n}}\right)-2^{n} f\left(\frac{x}{2^{n}}\right), \frac{t}{2}\right), N\left(2^{n} f\left(\frac{x}{2^{n}}\right)-2^{n} L\left(\frac{x}{2^{n}}\right), \frac{t}{2}\right)\right\} \\
& \geq \min \left\{N^{\prime}\left(\varphi\left(\frac{x}{2^{n+1}}, 0,0\right), \frac{(1-2|r|) t}{2^{n+1}}\right), N^{\prime}\left(\varphi\left(\frac{x}{2^{n}}, \frac{x}{2^{n}}, 0\right), \frac{(1-2|r|) t}{2^{n+1}|r|}\right)\right\} \\
& \geq \min \left\{N^{\prime}\left(\varphi(x, 0,0), \frac{(1-2|r|) t}{|r|^{n} 2^{n+1}}\right), N^{\prime}\left(\varphi(x, x, 0), \frac{(1-2|r|) t}{2^{n+1}|r|^{n+1}}\right)\right\} \rightarrow 1 \text { as } n \rightarrow \infty
\end{aligned}
$$

for all $t>0$. Therefore, $A(x)=L(x)$ for all $x \in X$. This completes the proof.

Corollary 3.2. Let $X$ be a normed spaces and $\left(\mathbb{R}, N^{\prime}\right)$ a fuzzy Banach space. Assume that there exist real numbers $\theta \geq 0$ and $p>1$ such that an odd mapping $f: X \rightarrow Y$ satisfies the inequality

$$
\begin{aligned}
& N\left(r^{2} f\left(\frac{x+y+z}{r}\right)+r^{2} f\left(\frac{x-y+z}{r}\right)+r^{2} f\left(\frac{x+y-z}{r}\right)+r^{2} f\left(\frac{-x+y+z}{r}\right)\right. \\
& -4 f(x)-4 f(y)-4 f(z), t) \geq N^{\prime}\left(\theta\left(\|x\|^{p}+\|y\|^{p}+\|z\|^{p}\right), t\right)
\end{aligned}
$$

for all $x, y, z \in X$ and $t>0$. Then there is a unique additive mapping $A: X \rightarrow Y$ satisfying (1.1) and the inequality

$$
N(f(x)-A(x), t) \geq \min \left\{N^{\prime}\left(\theta\|x\|^{p}, \frac{\left(2^{p+1}-4\right) t}{2^{p}}\right), N^{\prime}\left(\theta\|x\|^{p},\left(2^{p}-2\right) t\right)\right\}
$$

Proof. Let $\phi(x, y, z):=\theta\left(\|x\|^{p}+\|y\|^{p}+\|z\|^{p}\right)$ and $|r|=2^{-p}$. Applying Theorem 3.1, we get the desired result.

Theorem 3.3. Assume that an odd mapping $f: X \rightarrow Y$ satisfies the inequality (3.1) and that $\phi: X^{3} \rightarrow Z$ is a mapping for which there is a constant $r \in \mathbb{R}$ satisfying $0<|r|$ $<2$ such that

$$
N^{\prime}(\varphi(x, y, z),|r| t) \geq N^{\prime}\left(\varphi\left(\frac{x}{2}, \frac{y}{2}, \frac{z}{2}\right), t\right)
$$

for all $x, y, z \in X$ and all $t>0$. Then there exists a unique additive mapping $A: X \rightarrow$ $Y$ satisfying (1.1) and the inequality

$$
N(f(x)-A(x), t) \geq \min \left\{N^{\prime}\left(\varphi(x, 0,0), \frac{2(2-|r| t)}{|r|}\right), N^{\prime}(\varphi(x, x, 0), 2(2-|r|) t)\right\}
$$

for all $x \in X$ and all $t>0$.

Proof. It follows from (3.6) that

$$
N\left(\frac{f(2 x)}{2}-f(x), \frac{t}{4}\right) \geq \min \left\{N^{\prime}(\varphi(2 x, 0,0), t), N^{\prime}(\varphi(x, x, 0), t)\right\}
$$

for all $x \in X$ and all $t>0$. Replacing $x$ by $2^{n} x$ in (3.15), we obtain

$$
\begin{aligned}
N\left(\frac{f\left(2^{n+1} x\right)}{2^{n+1}}-\frac{f\left(2^{n} x\right)}{2^{n}}, \frac{t}{2^{n+2}}\right) & \geq \min \left\{N^{\prime}\left(\varphi\left(2^{n+1} x, 0,0\right), t\right), N^{\prime}\left(\varphi\left(2^{n} x, 2^{n} x, 0\right), t\right)\right\} \\
& \geq \min \left\{N^{\prime}\left(\varphi(x, 0,0), \frac{t}{|r|^{n+1}}\right), N^{\prime}\left(\varphi(x, x, 0), \frac{t}{|r|^{n}}\right)\right\} .
\end{aligned}
$$


So

$$
N\left(\frac{f\left(2^{n+1} x\right)}{2^{n+1}}-\frac{f\left(2^{n} x\right)}{2^{n}}, \frac{|r|^{n} t}{2^{n+2}}\right) \geq \min \left\{N^{\prime}\left(\varphi(x, 0,0), \frac{t}{|r|}\right), N^{\prime}(\varphi(x, x, 0), t)\right\}
$$

for all $x \in X$ and all $t>0$. Proceeding as in the proof of Theorem 3.1, we obtain that

$$
N\left(f(x)-\frac{f\left(2^{n} x\right)}{2^{n}}, \sum_{j=0}^{n-1} \frac{|r|^{j} t}{2^{j+2}}\right) \geq \min \left\{N^{\prime}\left(\varphi(x, 0,0), \frac{t}{|r|}\right), N^{\prime}(\varphi(x, x, 0), t)\right\}
$$

for all $x \in X$, all $t>0$ and any integer $n>0$. So

$$
\begin{aligned}
N\left(f(x)-\frac{f\left(2^{n} x\right)}{2^{n}}, t\right) & \geq \min \left\{N^{\prime}\left(\varphi(x, 0,0), \frac{t}{|r| \sum_{j=0}^{n-1} \frac{|r|^{j}}{2^{j+2}}}\right), N^{\prime}\left(\varphi(x, x, 0), \frac{t}{\sum_{j=0}^{n-1} \frac{|r|^{j}}{2^{j+2}}}\right)\right\} \\
& \geq \min \left\{N^{\prime}\left(\varphi(x, 0,0), \frac{2(2-|r| t)}{|r|}\right), N^{\prime}(\varphi(x, x, 0), 2(2-|r|) t)\right\} .
\end{aligned}
$$

The rest of the proof is similar to the proof of Theorem 3.1.

Corollary 3.4. Let $X$ be a normed spaces and that $\left(\mathbb{R}, N^{\prime}\right)$ a fuzzy Banach space. Assume that there exist real numbers $\theta \geq 0$ and $0<p<1$ such that an odd mapping $f$ : $X \rightarrow Y$ satisfies (3.12). Then there is a unique additive mapping $A: X \rightarrow Y$ satisfying (1.1) and the inequality

$$
N(f(x)-A(x), t) \geq \min \left\{N^{\prime}\left(\theta\|x\|^{p}, \frac{2\left(2-2^{p}\right)}{2^{p}}\right), N^{\prime}\left(\theta\|x\|^{p},\left(2-2^{p}\right) t\right)\right\}
$$

Proof. Let $\phi(x, y, z):=\theta\left(\|x\|^{p}+\|y\|^{p}+\|z\|^{p}\right)$ and $|r|=4^{p}$. Applying Theorem 3.3, we get the desired results.

Theorem 3.5. Assume that a mapping $f: X \rightarrow Y$ is an even mapping satisfies (3.1) and $f(0)=0$ and that $\phi: X^{3} \rightarrow Z$ is a mapping for which there is a constant $r \in \mathbb{R}$ satisfying $0<|r|<4$ such that

$$
N^{\prime}(\varphi(x, y, z),|r| t) \geq N^{\prime}\left(\varphi\left(\frac{x}{2}, \frac{y}{2}, \frac{z}{2}\right), t\right)
$$

for all $x, y, z \in X$ and all $t>0$. Then there exists a unique quadratic mapping $Q: X$ $\rightarrow Y$ satisfying (1.1) and the inequality

$$
N(f(x)-Q(x), t) \geq \min \left\{N^{\prime}\left(\varphi(x, 0,0), \frac{2(4-|r|) t}{|r|}\right), N^{\prime}(\varphi(x, x, 0),(4-|r|) t)\right\}
$$

for all $x \in X$ and all $t>0$.

Proof. Putting $y=x$ and $z=0$ in (3.1), we get

$$
N\left(2 r^{2} f\left(\frac{2 x}{r}\right)-8 f(x), t\right) \geq N^{\prime}(\varphi(x, x, 0), t)
$$

for all $x \in X$ and all $t>0$. Putting $y=z=0$ and replacing $x$ by $2 x$ in (3.1), we have

$$
N\left(4 r^{2} f\left(\frac{2 x}{r}\right)-4 f(2 x), t\right) \geq N^{\prime}(\varphi(2 x, 0,0), t)
$$


for all $x \in X$ and all $t>0$. By (3.20), (3.21), (N3) and (N4), we get

$$
\begin{aligned}
N\left(\frac{f(2 x)}{4}-f(x), \frac{t}{16}\right) & =N\left(2\left(2 r^{2} f\left(\frac{2 x}{r}\right)-8 f(x)\right)-\left(4 r^{2} f\left(\frac{2 x}{r}\right)-4 f(2 x)\right), t\right) \\
& \geq \min \left\{N\left(2 r^{2} f\left(\frac{2 x}{r}\right)-8 f(x), \frac{t}{4}\right), N\left(4 r^{2} f\left(\frac{2 x}{r}\right)-4 f(2 x), \frac{t}{2}\right)\right\} \\
& \geq \min \left\{N^{\prime}\left(\varphi(x, x, 0), \frac{t}{4}\right), N^{\prime}\left(\varphi(2 x, 0,0), \frac{t}{2}\right)\right\}
\end{aligned}
$$

for all $x \in X$ and all $t>0$. Replacing $x$ by $2^{n} x$ in (3.22), we obtain

$$
\begin{aligned}
N\left(\frac{f\left(2^{n+1}\right) x}{4^{n+1}}-\frac{f\left(2^{n} x\right)}{4^{n}}, \frac{t}{4^{n+2}}\right) & \geq \min \left\{N^{\prime}\left(\varphi\left(2^{n} x, 2^{n} x, 0\right), \frac{t}{4}\right), N^{\prime}\left(\varphi\left(2^{n+1} x, 0,0\right), \frac{t}{2}\right)\right\} \\
& \geq \min \left\{N^{\prime}\left(\varphi(x, x, 0), \frac{t}{4|r|^{n}}\right), N^{\prime}\left(\varphi(x, 0,0), \frac{t}{2|r|^{n+1}}\right)\right\}
\end{aligned}
$$

for all $x \in X$ and all $t>0$. Proceeding as in the proof of Theorem 3.1, we obtain that

$$
N\left(f(x)-\frac{f\left(2^{n} x\right)}{4^{n}}, \sum_{j=0}^{n-1} \frac{|r|^{j} t}{4^{j+2}}\right) \geq \min \left\{N^{\prime}\left(\varphi(x, x, 0), \frac{t}{4}\right), N^{\prime}\left(\varphi(x, 0,0), \frac{t}{2|r|}\right)\right\}
$$

for all $x \in X$, all $t>0$ and any integer $n>0$. So

$$
\begin{aligned}
N\left(f(x)-\frac{f\left(2^{n} x\right)}{4^{n}}, t\right) & \geq \min \left\{N^{\prime}\left(\varphi(x, x, 0), \frac{4 t}{\sum_{j=0}^{n-1} \frac{|r|^{j}}{4 j}}\right), N^{\prime}\left(\varphi(x, 0,0), \frac{8 t}{|r| \sum_{j=0}^{n-1} \frac{|r|^{j}}{4^{j}}}\right)\right\} \\
& \geq \min \left\{N^{\prime}\left(\varphi(x, 0,0), \frac{2(4-|r| t)}{|r|}\right), N^{\prime}(\varphi(x, x, 0),(4-|r|) t)\right\} .
\end{aligned}
$$

The rest of the proof is similar to the proof of Theorem 3.5.

Corollary 3.6. Let $X$ be a normed spaces and $\left(\mathbb{R}, N^{\prime}\right)$ a fuzzy Banach space. Assume that there exist real numbers $\theta \geq 0$ and $0<p<1$ such that an even mapping $f: X \rightarrow Y$ satisfies (3.12). Then there is a unique quadratic mapping $Q: X \rightarrow Y$ satisfying (1.1) and the inequality

$$
N(f(x)-Q(x), t) \geq \min \left\{N^{\prime}\left(\theta\|x\|^{p}, \frac{2\left(4-4^{p}\right) t}{4^{p}}\right), N^{\prime}\left(\theta\|x\|^{p}, \frac{\left(4-4^{p}\right) t}{2}\right)\right\}
$$

Proof. Let $\phi(x, y, z):=\theta\left(\|x\|^{p}+\|y\|^{p}+\|z\|^{p}\right)$ and $|r|=4^{p}$. Applying Theorem 3.1, we get the desired result.

Theorem 3.7. Assume that an even mapping $f: X \rightarrow Y$ satisfies the inequality (3.1) and $f(0)=0$ and that $\phi: X^{3} \rightarrow Z$ is a mapping for which there is a constant $r \in \mathbb{R}$ satisfying $0<|r|<\frac{1}{4}$ such that

$$
N^{\prime}\left(\varphi\left(\frac{x}{2}, \frac{y}{2}, \frac{z}{2}\right), t\right) \geq N^{\prime}\left(\varphi(x, y, z), \frac{t}{|r|}\right)
$$

for all $x, y, z \in X$ and all $t>0$. Then there exists a unique quadratic mapping $Q: X$ $\rightarrow Y$ satisfying (1.1) and the inequality

$$
N(f(x)-Q(x), t) \geq \min \left\{N^{\prime}\left(\varphi(x, x, 0), \frac{(1-4|r| t)}{|r|}\right), N^{\prime}(\varphi(x, 0,0),(2-8|r|) t)\right\}
$$

for all $x \in X$ and all $t>0$. 
Proof. It follows from (3.22) that

$$
N\left(f(x)-4 f\left(\frac{x}{2}\right), \frac{t}{4}\right) \geq \min \left\{N^{\prime}\left(\varphi\left(\frac{x}{2}, \frac{x}{2}, 0\right), \frac{t}{4}\right), N^{\prime}\left(\varphi(x, 0,0), \frac{t}{2}\right)\right\}
$$

for all $x \in X$ and all $t>0$. Replacing $x$ by $\frac{x}{2^{j}}$ in (3.25), we have

$$
N\left(4^{j+1} f\left(\frac{x}{2^{j+1}}\right)-4^{j} f\left(\frac{x}{2^{j}}\right), 4^{j} t\right) \geq \min \left\{N^{\prime}\left(\varphi(x, x, 0), \frac{t}{|r|^{j+1}}\right), N^{\prime}\left(\varphi(x, 0,0), \frac{2 t}{|r|^{j}}\right)\right\}
$$

for all $x \in X$, all $t>0$ and any integer $j \geq 0$. By the same technique as in Theorem 3.1 , we find that

$$
\begin{aligned}
N\left(f(x)-4^{n} f\left(\frac{x}{2^{n}}\right), t\right) & \geq \min \left\{N^{\prime}\left(\varphi(x, x, 0), \frac{t}{\sum_{j=0}^{n-1} 4^{j}|r|^{j+1}}\right), N^{\prime}\left(\varphi(x, 0,0), \frac{2 t}{\sum_{j=0}^{n-1} 4^{j}|r|^{j}}\right)\right\} \\
& \geq \min \left\{N^{\prime}\left(\varphi(x, x, 0), \frac{(1-4|r|) t}{|r|}\right), N^{\prime}(\varphi(x, 0,0),(2-8|r|) t)\right\}
\end{aligned}
$$

The rest of the proof is similar to the proof of Theorem 3.1.

Corollary 3.8. Let $X$ be a normed spaces and $\left(\mathbb{R}, N^{\prime}\right)$ a fuzzy Banach space. Assume that there exists real numbers $\theta \geq 0$ and $p>1$ such that an even mapping $f: X \rightarrow Y$ satisfies (3.12) and $f(0)=0$. Then there is a unique quadratic mapping $Q: X \rightarrow Y$ satisfying (1.1) and the inequality

$$
N(f(x)-Q(x), t) \geq \min \left\{N^{\prime}\left(\theta\|x\|^{p}, \frac{\left(4^{p}-4 t\right)}{2}\right), N^{\prime}\left(\theta\|x\|^{p},\left(2-\frac{8}{4^{p}}\right) t\right)\right\}
$$

Proof. Let $\phi(x, y, z):=\theta\left(\|x\|^{p}+\|y\|^{p}+\|z\|^{p}\right)$ and $|r|=4^{-p}$. Applying Theorem 3.7, we get the desired results.

Let $f: X \rightarrow Y$ be a mapping satisfying $f(0)=0$ and (1.1). Let $f_{e}(x):=\frac{f(x)+f(-x)}{2}$ and $f_{o}(x)=\frac{f(x)-f(-x)}{2}$. Then $f_{e}$ is an even mapping satisfying (1.1) and $f_{o}$ is an odd mapping satisfying (1.1) such that $f(x)=f_{e}(x)+f_{o}(x)$. So we obtain the following.

Theorem 3.9. Assume that a mapping $f: X \rightarrow Y$ is a mapping satisfying (3.1) and $f$ $(0)=0$ and that $\phi: X^{3} \rightarrow Z$ is a mapping for which there is a constant $r \in \mathbb{R}$ satisfying $0<|r|<\frac{1}{4}$ such that

$$
N^{\prime}\left(\varphi\left(\frac{x}{2}, \frac{y}{2}, \frac{z}{2}\right), t\right) \geq N^{\prime}\left(\varphi(x, y, z), \frac{t}{|r|}\right)
$$

for all $x, y, z \in X$ and all $t>0$. Then there exist a unique additive mapping $A: X \rightarrow$ $Y$ and a unique quadratic mapping $Q: X \rightarrow Y$ satisfying (1.1) and the inequality

$$
\begin{aligned}
& N(f(x)-A(x)-Q(x), 2 t) \\
& \geq \min \left\{\min \left\{N^{\prime} \varphi(x, 0,0), 2(1-2|r| t), N^{\prime}\left(\varphi(x, x, 0), \frac{2(1-2)|r| t}{|r|}\right)\right\},\right. \\
& \left.\min \left\{N^{\prime}\left(\varphi(x, 0,0), \frac{(1-4|r|) t}{|r|}\right), N^{\prime}(\varphi(x, 0,0),(2-8|r|) t)\right\}\right\}
\end{aligned}
$$

for all $x \in X$ and all $t>0$. 
Proof. It follows from Theorems 3.1 and 3.7 that

$$
\begin{aligned}
& N(f(x)-A(x)-Q(x), 2 t) \\
& =N\left(\frac{f(x)+f(-x)}{2}+\frac{f(x)-f(-x)}{2}-A(x)-Q(x), 2 t\right) \\
& \geq \min \left\{N\left(\frac{f(x)+f(-x)}{2}-Q(x), t\right), N\left(\frac{f(x)-f(-x)}{2}-A(x), t\right)\right\} \\
& \geq \min \left\{\min \left\{N^{\prime}(\varphi(x, 0,0), 2(1-2|r|) t), N^{\prime}\left(\varphi(x, x, 0), \frac{2(1-2|r|) t}{|r|}\right)\right\},\right. \\
& \left.\min \left\{N^{\prime}\left(\varphi(x, 0,0), \frac{(1-4|r|) t}{|r|}\right), N^{\prime}(\varphi(x, 0,0),(2-8|r|) t)\right\}\right\} .
\end{aligned}
$$

Corollary 3.10. Let $X$ be a normed spaces and that $\left(\mathbb{R}, N^{\prime}\right)$ a fuzzy Banach space. Assume that there exists real number $\theta \geq 0$ and $0<p<1$ such that a mapping $f: X \rightarrow$ $Y$ satisfies (3.12) and $f(0)=0$. Then there are unique quadratic and additive mappings $Q: X \rightarrow Y$ and $A: X \rightarrow Y$ (respectively) satisfying (1.1) and the inequality

$$
N(f(x)--A(x)-Q(x), t) \geq \min \left\{N^{\prime}\left(\theta\|x\|^{p}, \frac{\left(1-4^{p+1}\right) t}{4^{p}}\right), N^{\prime}\left(\theta\|x\|^{p},\left(2-2.4^{p+1}\right) t\right)\right\}
$$

Proof. Let $\phi(x, y, z):=\theta\left(\|x\|^{p}+\|y\|^{p}+\|z\|^{p}\right)$ and $|r|=4^{p}$. Applying Theorem 3.7, we get the desired results.

\section{Acknowledgements}

The authors' Jung Rye Lee and Dong Yun Shin were supported by the Basic Science Research Program through the National Research Foundation of Korea funded by the Ministry of Education, Science and Technology (NRF-20100009232) and (NRF-2010-0021792), respectively.

\section{Author details}

${ }^{1}$ Department of Mathematics, College of Sciences, Yasouj University, Yasouj 75914-353, Iran ${ }^{2}$ Department of Mathematics, Islamic Azad University, Firoozabad Branch, Firoozabad, Iran ${ }^{3}$ Department of Mathematics, Daejin University, Kyeonggi 487-711, Korea ${ }^{4}$ Department of Mathematics, University of Seoul, Seoul 130-743, Korea

\section{Authors' contributions}

All authors conceived of the study, participated in its design and coordination, drafted the manuscript, participated in the sequence alignment, and read and approved the final manuscript.

\section{Competing interests}

The authors declare that they have no competing interests.

Received: 19 November 2011 Accepted: 14 March 2012 Published: 14 March 2012

\section{References}

1. Ulam, SM: Problems in Modern Mathematics. Wiley, New York (1964)

2. Hyers, DH: On the stability of the linear functional equation. Proc Natl Acad Sci USA. 27, 222-224 (1941). doi:10.1073/ pnas.27.4.222

3. Rassias, TM: On the stability of the linear mapping in Banach spaces. Proc Am Math Soc. 72, 297-300 (1978). doi:10.1090/S0002-9939-1978-0507327-1

4. Găvruta, P: A generalization of the Hyers-Ulam-Rassias stability of approximately additive mappings. J Math Anal Appl. 184, 431-436 (1994). doi:10.1006/jmaa.1994.1211

5. Skof, F: Local properties and approximation of operators. Rendiconti del Seminario Matematico e Fisico di Milano. 53, 113-129 (1983). doi:10.1007/BF02924890

6. Cholewa, PW: Remarks on the stability of functional equations. Aequationes Mathematicae. 27, 76-86 (1984). doi:10.1007/BF02192660

7. Czerwik, S: On the stability of the quadratic mapping in normed spaces. Abh Math Sem Univ Hambg. 62, 239-248 (1992)

8. Katsaras, AK: Fuzzy topological vector spaces. Fuzzy Sets Syst. 12, 143-154 (1984). doi:10.1016/0165-0114(84)90034-4

9. Felbin, C: Finite-dimensional fuzzy normed linear space. Fuzzy Sets Syst. 48, 239-248 (1992). doi:10.1016/0165-0114(92) 90338-5

10. Krishna, SV, Sarma, KKM: Separation of fuzzy normed linear spaces. Fuzzy Sets Syst. 63, 207-217 (1994). doi:10.1016/ 0165-0114(94)90351-4 
11. Mihet, D, Radu, V: On the stability of the additive Cauchy functional equation in random normed spaces. J Math Anal Appl. 343, 567-572 (2008). doi:10.1016/j.jmaa.2008.01.100

12. Mohammadi, M, Cho, Y, Park, C, Vetro, P, Saadati, R: Random stability of an additive-quadratic-quartic functional equation. J Inequal Appl 2010, 18 (2010). Article ID 754210

13. Najati, A, Cho, Y: Generalized Hyers-Ulam stability of the Pexiderized Cauchy functional equation in non-Archimedean spaces. Fixed Point Theory Appl 2011, 11 (2011). Article ID 309026. doi:10.1186/1687-1812-2011-11

14. Najati, A, Kang, J, Cho, Y: Local stability of the Pexiderized Cauchy and Jensen's equations in fuzzy spaces. J Inequal Appl. 2011(78):8 (2011)

15. Park, C: On the stability of the linear mapping in Banach modules. J Math Anal Appl. 275, 711-720 (2002). doi:10.1016/ 50022-247X(02)00386-4

16. Park, C: Modefied Trif's functional equations in Banach modules over a $C^{*}$-algebra and approximate algebra homomorphism. J Math Anal Appl. 278, 93-108 (2003). doi:10.1016/S0022-247X(02)00573-5

17. Park, C: Fuzzy stability of a functional equation associated with inner product spaces. Fuzzy Sets Syst. 160, 1632-1642 (2009). doi:10.1016/j.fss.2008.11.027

18. Bag, T, Samanta, SK: Finite dimensional fuzzy normed linear spaces. J Fuzzy Mathe. 11, $687-705$ (2003)

19. Cheng, SC, Mordeson, JN: Fuzzy linear operators and fuzzy normed linear spaces. Bull Calcutta Math Soc. 86, 429-436 (1994)

20. Karmosil, I, Michalek, J: Fuzzy metric and statistical metric spaces. Kybernetica. 11, $326-334$ (1975)

21. Bag, T, Samanta, SK: Fuzzy bounded linear operators. Fuzzy Sets Syst. 151, 513-547 (2005). doi:10.1016/j.fss.2004.05.004

22. Lee, S, Jun, K: Hyers-Ualm-Rassias stability of quadratic type functional equation. Bull Korean Math Soc. 40, 183-193 (2003)

23. Kenary, HA: On the stability of a cubic functional equation in random normed spaces. J Math Ext. 4, 105-114 (2009)

24. Kenary, HA: On the Hyers-Rassias stability of the Pexiderial functional equation. Ital J Pure Appl Math. (to appear)

25. Kenary, HA, Cho, Y: Stability of mixed additive-quadratic Jensen type functional equation in various spaces. Comput Math Appl. 61, 2704-2724 (2011). doi:10.1016/j.camwa.2011.03.024

26. Kenary, HA: Stability of a Pexiderial functional equation in random normed spaces. Rendiconti Del Circolo Mathematico Di Palermo. 60, 59-68 (2011). doi:10.1007/s12215-011-0027-5

27. Jung, S: Hyers-Ulam-Rassias Stability of Functional Equations in Mathematical Analysis. Hadronic Press, Palm Harbor (2001)

28. Rassias, TM: On the stability of the quadratic functional equation and it's application. pp. 89-124. Studia Univ. Babes Bolyai XLIII (1998)

29. Rassias, TM: On the stability of functional equations in Banach spaces. J Math Anal Appl. 251, 264-284 (2000). doi:10.1006/jmaa.2000.7046

30. Cho, Y, Park, C, Saadati, R: Fuzzy functional inequalities. J Comput Anal Appl. 13, 305-320 (2011)

31. Cho, Y, Park, C, Saadati, R: Functional inequalities in non-Archimedean Banach spaces. Appl Math Lett. 60, 1994-2002 (2010)

32. Eshaghi Gordji, M, Park, C, Savadkouhi, MB: The stability of quartic functional equation with the fixed point alternative. Fixed Point Theory. 11, 265-272 (2010)

33. Rassias, TM, Šemrl, P: On the Hyers-Ulam stability of linear mappings. J Math Anal Appl. 173, 325-338 (1993). doi:10.1006/jmaa.1993.1070

doi:10.1186/1029-242X-2012-64

Cite this article as: Azadi Kenary et al: Fuzzy Hyers-Ulam approximation of a mixed AQ mapping. Journal of

Inequalities and Applications 2012 2012:64.

\section{Submit your manuscript to a SpringerOpen ${ }^{\circ}$ journal and benefit from:}

- Convenient online submission

- Rigorous peer review

- Immediate publication on acceptance

- Open access: articles freely available online

- High visibility within the field

- Retaining the copyright to your article

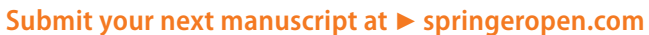

